\title{
Article \\ Vibrational Spectra and Molecular Vibrational Behaviors of Dibenzyl Disulfide, Dibenzyl Sulphide and Bibenzyl
}

\author{
Ziyi Wang (D), Ruimin Song, Weigen Chen*, Jianxin Wang, Pinyi Wang, Zhixian Zhang (D), Xinyuan Zhang \\ and Fu Wan \\ State Key Laboratory of Power Transmission Equipment \& System Security and New Technology, \\ Chongqing University, Chongqing 400044, China; wzycsust@163.com (Z.W.); ruiminsong@cqu.edu.cn (R.S.); \\ wang.jianxin@cqu.edu.cn (J.W.); wang.pinyi@outlook.com (P.W.); zhang.zhixian@cqu.edu.cn (Z.Z.); \\ 18846116694@163.com (X.Z.); fuwan@cqu.edu.cn (F.W.) \\ * Correspondence: weigench@cqu.edu.cn
}

check for updates

Citation: Wang, Z.; Song, R.; Chen, W.; Wang, J.; Wang, P.; Zhang, Z.; Zhang, X.; Wan, F. Vibrational Spectra and Molecular Vibrational Behaviors of Dibenzyl Disulfide, Dibenzyl Sulphide and Bibenzyl. Int. J. Mol. Sci. 2022, 23, 1958. https://doi.org/ $10.3390 /$ ijms 23041958

Academic Editor: Georgiy V. Girichev

Received: 20 January 2022 Accepted: 5 February 2022 Published: 10 February 2022

Publisher's Note: MDPI stays neutral with regard to jurisdictional claims in published maps and institutional affiliations.

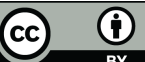

Copyright: (c) 2022 by the authors. Licensee MDPI, Basel, Switzerland. This article is an open access article distributed under the terms and conditions of the Creative Commons Attribution (CC BY) license (https:// creativecommons.org/licenses/by/ $4.0 /)$.

\begin{abstract}
The vibration spectroscopy (Raman and infrared) of widely concerned molecules in sulfur corrosion phenomenon (Dibenzyl Disulfide, Dibenzyl Sulphide, and Bibenzyl) is detailedly analyzed based on density functional theory and experimental measurement. The dominant conformations of these molecules are determined according to Boltzmann distribution in relative Gibbs free energy. Additionally, noncovalent interaction analysis is conducted to indicate intramolecular interaction. Vibration normal mode is assigned based on potential energy distribution, which comprehensively reveals the molecular vibrational behaviors. Conformations weighted spectra are obtained and compared with experimentally measured spectra. We found that experimental spectra are in good agreement with the theoretical spectra in B3LYP-D3(BJ)/6-311G** level with a frequency correction factor. Furthermore, the divergence among these molecules is discussed. The vibrational behavior of the methylene group in the molecule shows a trend with the presence of the sulfur atom.
\end{abstract}

Keywords: Raman spectroscopy; infrared spectroscopy; corrosive sulfur; density functional theory; vibration assignment

\section{Introduction}

Nowadays, the sulfur corrosion problem of power equipment has received widespread concern [1-5]. The failures caused by corrosive sulfur greatly affect the safety and stability of the power system and result in substantial economic losses. Dibenzyl Disulfide (DBDS) is regarded as the most important corrosive sulfur. The corrosion mechanism was proposed by Mitsubishi Electric Corporation as shown in Figure 1 [6]. The intermediate product Dibenzyl Sulphide (DBS) is also corrosive, and the final product of this reaction is Bibenzyl $(\mathrm{BiBz})$ and cuprous sulfide. The DBDS, DBS, and BiBz are considered as indicators in power equipment sulfur corrosion phenomenon. The study on their physical and chemical properties will contribute to the development of advanced corrosive resistant materials and the realization of corrosive state monitoring.<smiles>ClC(=Cc1cccc(CS(Cl)(Cl)Cl)c1)Cc1cccc(CSSCc2ccccc2)c1</smiles><smiles>CC(C)(C)c1cccc(CCc2cccc(-c3ccc(CSCc4cccc(CSS(Cl)(Cl)(Cl)(Cl)Cc5ccccc5)c4)cc3)c2)c1</smiles><smiles>CC(C)c1cccc(CCc2cccc(C=[Ge]3C=CC=C(CSCc4ccccc4)C3)c2)c1</smiles>

Figure 1. The corrosion mechanism of DBDS in power equipment. 
Numerous efforts have been made to study properties of the DBDS, DBS, and BiBz, including chemical reactivity [7,8], synergistic effect [9,10], detection methods [6,11], etc. [12,13]. In this paper, the vibrational spectra and molecular vibrational behaviors are analyzed detailedly. The vibrational spectroscopy includes infrared and Raman spectroscopy, which is based on periodic changes of dipolmoments (IR) or polarizabilities (Raman) caused by molecular vibrations behaviors. IR and Raman spectra are both widely used methods for composition analysis and trace detection [14-16].

In addition to experimentally measured vibrational spectra, density functional theory (DFT) provides a solid foundation of theoretically calculated spectra. Considering the presence of a large number of fundamentals and overtones bands, it is difficult to interpret experimental spectra of large molecule [17]. However, the conformational distribution and theoretical spectrum of molecules can be obtained based on DFT. Then, a potential energy distribution (PED) based analysis can be performed to achieve vibration assignment, which gives a clear and crispy concept about the structural-vibrational properties of the molecule. A lot of studies have recently appeared in the literature concerning the calculation of spectroscopic properties by DFT methods [17-22].

\section{Experimental Section}

A commercially available Fourier transform infrared spectroscopy (FTIR, Nicolet iS50 FT-IR) was utilized for experimental test. The DBDS (CAS:150-60-7, 98\%, Aladdin, China), DBS (CAS:538-74-9, 99\%, Aladdin, China), and BiBz (CAS:103-29-7, 99\%, Aladdin, China) samples were mixed with $\mathrm{KBr}$ (CAS:7758-02-3, 99.5\%, Aladdin, China) and ground in a agate mortar for $1 \mathrm{~min}$. Then, the mixed sample was pressurized by a tablet press at $20 \mathrm{MPa}$ for $2 \mathrm{~min}$ for transmission testing. The IR spectra were measured between $400 \mathrm{~cm}^{-1}$ to $4000 \mathrm{~cm}^{-1}$ at a $4 \mathrm{~cm}^{-1}$ resolution. The spectra were an average of 32 scans.

A confocal Raman spectrometer mentioned in our previous paper [23] was used to detect experimental spectra of the DBDS, DBS, and BiBz. There are three kinds of gratings (600 lines / mm, 1200 lines $/ \mathrm{mm}$, and 1800 lines $/ \mathrm{mm}$ ) built in the spectrometer. The grating with minor grooves number is designed for wide spectral range detection, although the spectral resolution will decrease. In order to compare with theoretical spectra in full spectral range, 600 lines $/ \mathrm{mm}$ grating was adopted. The other test parameters of the measurement are listed below: the slit width was $50 \mathrm{um}$, the integration time was $1 \mathrm{~s}$, and the integration number was 20 times. The Raman platform was calibrated with monocrystalline silicon before each test. The Raman shift of the first-order silicon peak was adjusted to $520.7 \mathrm{~cm}^{-1}$. The result of Raman spectrum comes from the average of three measurements.

The Raman/IR spectra of DBDS, DBS, and BiBz were plotted in Section 4 after normalization and de-baseline operations.

\section{Molecular Structure and Intramolecular Interaction}

\subsection{Conformation Determination}

Flexible molecules always have multiple conformations, such as DBDS, DBS, and BiBz studied in this paper. The proportion of different conformations was calculated according to Boltzmann distribution in relative Gibbs free energy. The molecular conformation search program Molclus [24] is used for conformation determination in this paper.

Firstly, a batch of initial conformations of DBDS, DBS, and BiBz were generated by rotating chemical bond via Molclus. The chemical bond within the benzene ring was ignored; only C-C bonds, C-S bonds, and S-S bonds between benzene rings are considered. All the considered bonds rotate every $120^{\circ}$. The DBDS with five rotation bonds generates a total of $3^{5}$ initial conformations. Similarly, DBS generates $3^{4}$ initial conformations. BiBz generates $3^{3}$ initial conformations.

All initial conformations generated above were pre-optimized geometrically by Gaussian [25] in a semi-empirical method PM7 [26]. The optimized conformations with the energy difference within $0.25 \mathrm{kcal} / \mathrm{mol}$ and the geometric difference within $0.1 \AA$ will be classified as the same conformation. The conformations with relatively lower energy 
were applied further geometric optimization and frequency analysis in B3LYP-D3(BJ) /6$311 G^{* *}$ [27-31] level. For an authentic conformation distribution, a double hybrid functional revDSD-PBEP86-D3(BJ) [32] in conjunction with may-cc-PVTZ [33] was introduced to recalculate the single point energy. The single point can be added with thermal correction to find the precise Gibbs free energy. The thermal correction is obtained in frequency analysis based on rigid-rotor harmonic oscillator (RRHO) model [34] under 298.15K and $1 \mathrm{~atm}$. The results are shown in Table 1.

Table 1. Energy and conformation proportion of DBDS, DBS, and BiBz.

\begin{tabular}{cccccc}
\hline Molecule & Conformation & $\begin{array}{c}\text { Single Point } \\
\text { Energy (a.u.) }\end{array}$ & $\begin{array}{c}\text { Thermal } \\
\text { Correction (a.u.) }\end{array}$ & $\begin{array}{c}\text { Gibbs Free } \\
\text { Energy (a.u.) }\end{array}$ & Proportion \\
& 1 & -541.04114860 & 0.198497 & -540.8426516 & $55.17 \%$ \\
BiBz & 2 & -541.03965980 & 0.197204 & -540.8424558 & $44.83 \%$ \\
\hline \multirow{2}{*}{ DBS } & 1 & -938.9390301 & 0.196498 & -938.7425321 & $91.45 \%$ \\
& 2 & -938.9372458 & 0.197657 & -938.7395888 & $4.50 \%$ \\
& 3 & -938.9338298 & 0.194142 & -938.7396878 & $4.05 \%$ \\
\hline \multirow{2}{*}{ DBDS } & 1 & -1336.847129 & 0.195781 & -1336.651348 & $53.12 \%$ \\
& 2 & -1336.847175 & 0.195965 & -1336.65121 & $45.89 \%$ \\
& 3 & -1336.844026 & 0.197072 & -1336.646954 & $0.51 \%$ \\
\hline
\end{tabular}

Conformations in Table 1 with a proportion less than 5\% were ignored. The geometric structures and surface electrostatic potential of several dominant conformations were visualized via VMD [35], as shown in Figure 2. The electrostatic potential involved was evaluated by Multiwfn, based on the highly effective algorithm proposed in ref. [36].

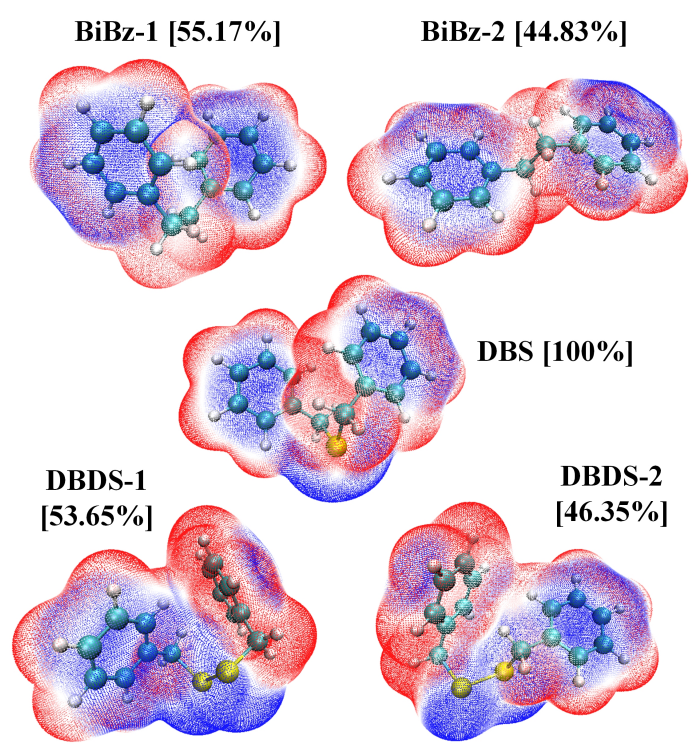

Figure 2. The geometric structure and surface electrostatic potential of the dominant conformation.

It can be found from the surface electrostatic potential distribution that the negative charge region mainly occurs around the sulfur atom and the benzene ring planar center. It is difficult to explain the geometric structure only by the surface electrostatic potential distribution due to the existence of various intramolecular interaction. Further NCI analysis is thus needed.

\subsection{Noncovalent Interaction Analysis of the Dominant Conformation}

To reveal the nature of these dominant conformations with low free energy, the noncovalent interaction (NCI) [37] method was applied for weak molecular interactions analysis. 
The NCI method uses Reduced Density Gradient (RDG) to distinguish regions with noncovalent interactions in the system. The expression of RDG is as follows, where $\rho$ is the electron density.

$$
\mathrm{RDG}=\frac{1}{2 \cdot \sqrt[3]{3 \pi^{2}}} \cdot \frac{|\nabla \rho|}{\rho^{4 / 3}}
$$

The noncovalent interactions areas can be determined by RDG value. However, the strength and type of interaction are determined by $\rho$ and $\operatorname{sign}\left(\lambda_{2}\right)$, respectively. The $\operatorname{sign}\left(\lambda_{2}\right)$ is the second largest eigenvalue of the electron density Hessian matrix. Overlapping the color map of $\operatorname{sign}\left(\lambda_{2}\right) \cdot \rho$, as shown in Figure 3, on the RDG value isosurface, means the areas, intensity, and type of the noncovalent interactions can be visualized at the same time.

(a)
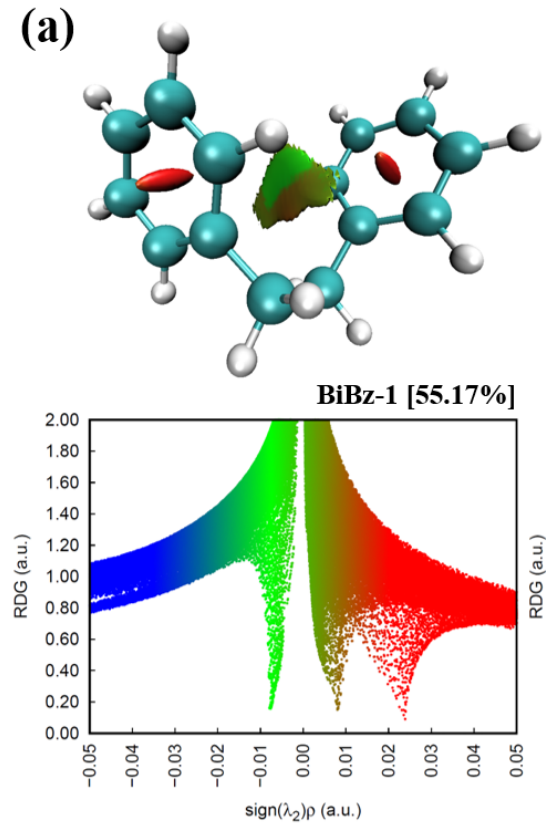

(d)

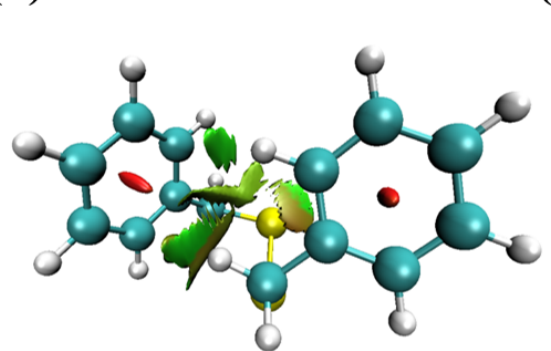

DBDS-1 $[53.65 \%]$

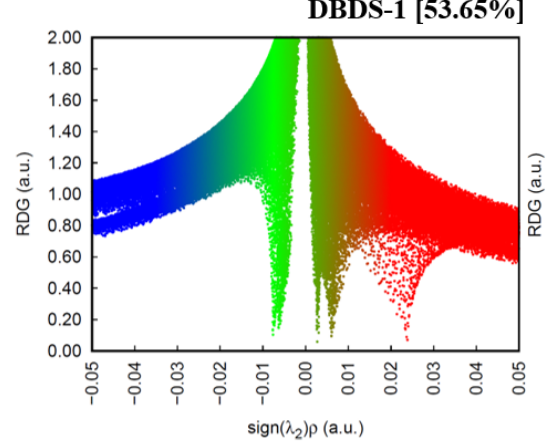

(b)
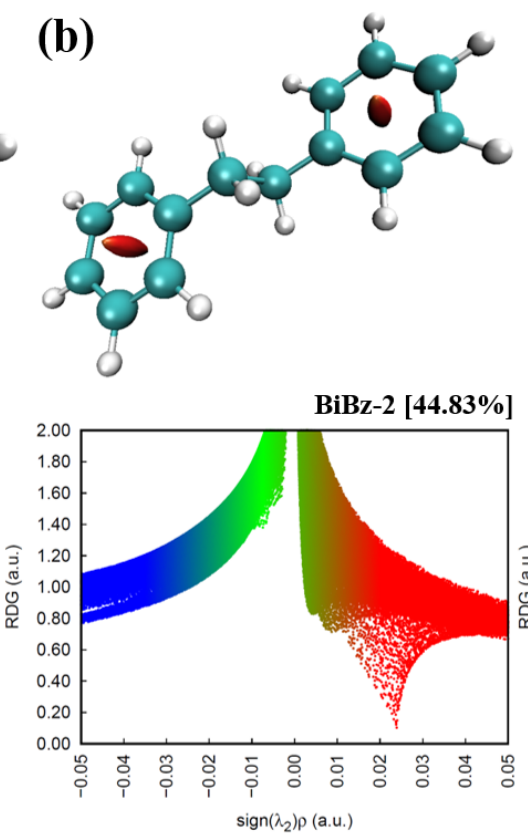

(e)
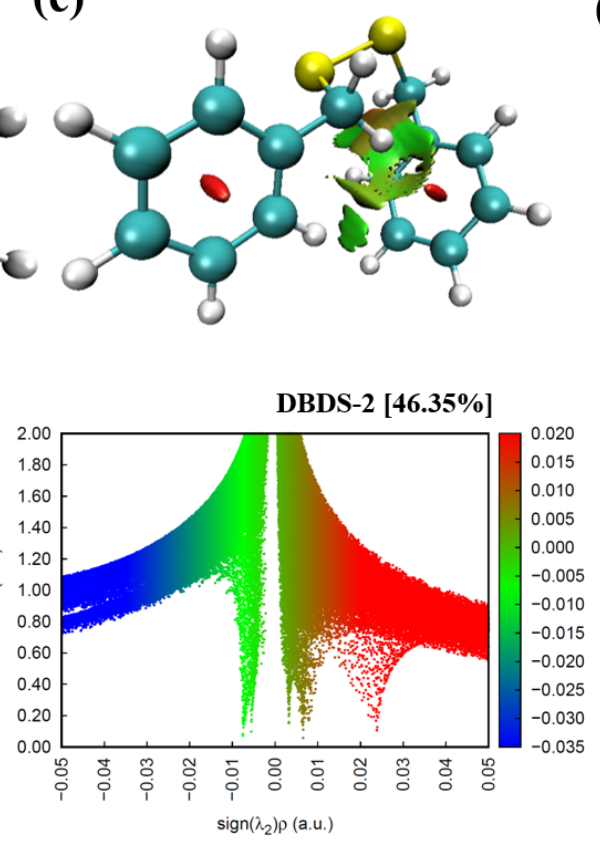
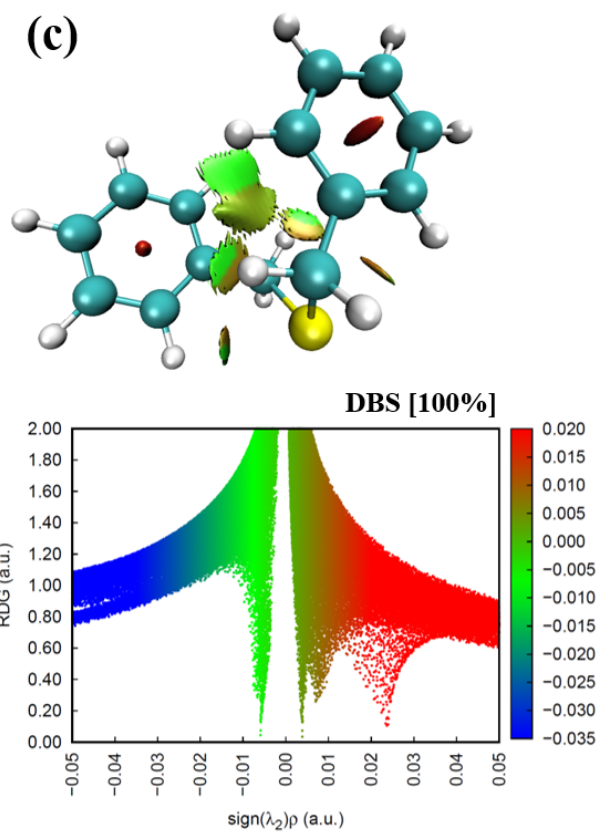

(f)

$+\mathbf{0 . 0 2}$

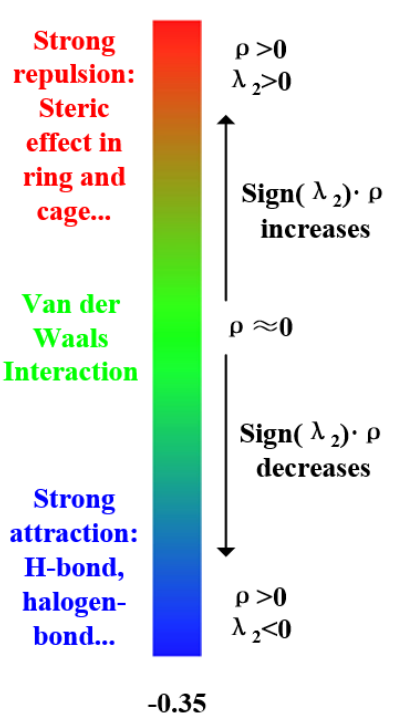

Figure 3. NCI analysis of dominant conformation. (a) RDG isosurface map and scatter plot of BiBz-1, (b) Bibz-2, (c) DBS, (d) DBDS-1, and (e) DBDS-2. (f) color map and chemical explanation. 
The isosurface map and scatter plot of five dominant conformations were visualized via Multiwfn [38,39] and VMD [35]. As described in Figure 3f, the red area in the isosurface map and the scatter plot indicates the repulsion between molecules, such as steric effect. The green area indicates the van der Waals interaction, while the blue area indicates hydrogen bonds and halogen bonds that have a significant attraction.

There are two common features in the five dominant conformations. Firstly, significant steric effect is observed in the two benzene rings. This steric effect is shown as a red spindleshaped area in the benzene ring on the RDG isosurface map, and as a red spike on the right side in the scatter plot. Secondly, there is no notable attraction in these conformations.

For $\mathrm{BiBz}-1$, the van der Waals interaction is formed between the two benzene rings. The molecular structure of BiBz-2 is stretched, the two benzene rings are far apart, and no significant van der Waals effect is observed. This was shown as two spikes near the zero point on the scatter plot. The spikes can be positive or negative as the sign of $\operatorname{sign}\left(\lambda_{2}\right) \cdot \rho$ is relatively unstable as the electron density in the van der Waals area is small. The BiBz-1 formed by two benzene rings attracting each other is more stable and has a lower single point energy due to intermolecular forces. However, as BiBz-2 has a lower thermal correction, the Gibbs free energy and proportion of these two conformations are not remarkably different.

For DBS, in addition to the zone between benzene rings, the van der Waals effect also occurs between the sulfur atom and the hydrogen atom on the benzene ring. However, this kind of H-S interaction is distinguished from hydrogen bonds (shown in blue). The RDG isosurface between the two benzene rings in DBDS is much more complicated, but in conclusion, it is still van der Waals interaction. These broken isosurfaces were shown as many fine spikes near the zero point on the scatter plot in Figure 3d,e.

\section{Vibration Analysis and Vibrational Spectra}

\subsection{PED Based Vibrational Assignment}

Each characteristic group in molecules has its own unique vibration behavior. However, these groups will be coupled with the molecular systems, which change frequency and intensity. Non-linear molecules have $3 n-6$ normal vibration modes, where $n$ is the number of atoms in the molecule. The normal modes are the coupling of multiple groups vibration. It is difficult to directly identify which groups and vibration types contribute to the normal mode.

PED (potential energy distribution) analysis is an effective method that decomposes the normal vibration mode into group characteristic vibrations. The contribution proportion of the group vibration can be obtained, and the vibrational features of normal mode can be revealed. In this paper, PED based vibrational assignment of DBDS, DBS, and BiBz was performed via VEDA4 program [40].

The non-linear molecule DBDS consists of 30 atoms, it has a total of 84 normal modes. Therefore, 84 linearly independent internal coordinates are introduced to describe molecular vibration. The internal coordinates and related atoms of the DBDS- 1 conformation are shown in Table 2. Atom numbers are listed in Figure 4. Additionally, the internal coordinates and related information of other four conformations can be found in Supplementary Material. The vibration type in VEDA4 program are divided into stretching $(v)$, bending $(\delta)$, and torsion $(\tau / \gamma)$, which correspond to specific internal coordinates. The stretching vibration involves two atoms. Bending vibration involves three atoms and torsion vibration involves four atoms. Among them, torsion can be further divided into two types: $\tau$ and $\gamma$. In many cases, the two definitions can describe the same atoms movement, but not always. $\tau$ ABCD means the dihedral angle between the ABC and BCD planes. $\gamma$ ABCD means the angle between the AD vector and the BCD plane (reffed from VEDA4 user document). 
Table 2. Internal coordinates and related atoms in DBDS-1.

\begin{tabular}{|c|c|c|c|c|c|}
\hline Stretching & Related Atoms & Bending & Related Atoms & Torsion & Related Atoms \\
\hline$v 1$ & $\mathrm{C}(1)-\mathrm{H}(7)$ & $\delta 30$ & $C(22)-C(25)-C(27)$ & $\tau 58$ & $\mathrm{H}(7)-\mathrm{C}(1)-\mathrm{C}(2)-\mathrm{C}(3)$ \\
\hline$v 2$ & $\mathrm{C}(2)-\mathrm{H}(8)$ & $\delta 31$ & $C(3)-C(12)-S(15)$ & $\tau 59$ & $\mathrm{H}(8)-\mathrm{C}(2)-\mathrm{C}(1)-\mathrm{C}(6)$ \\
\hline$v 3$ & $\mathrm{C}(4)-\mathrm{H}(9)$ & $\delta 32$ & $\mathrm{H}(7)-\mathrm{C}(1)-\mathrm{C}(2)$ & $\tau 60$ & $\mathrm{H}(9)-\mathrm{C}(4)-\mathrm{C}(5)-\mathrm{C}(6)$ \\
\hline$v 4$ & $\mathrm{C}(5)-\mathrm{H}(10)$ & $\delta 33$ & $\mathrm{H}(8)-\mathrm{C}(2)-\mathrm{C}(1)$ & $\tau 61$ & $\mathrm{H}(10)-\mathrm{C}(5)-\mathrm{C}(6)-\mathrm{C}(1)$ \\
\hline$v 5$ & $\mathrm{C}(6)-\mathrm{H}(11)$ & $\delta 34$ & $\mathrm{H}(9)-\mathrm{C}(4)-\mathrm{C}(5)$ & $\tau 62$ & $\mathrm{H}(11)-\mathrm{C}(6)-\mathrm{C}(1)-\mathrm{C}(2)$ \\
\hline$v 6$ & $\mathrm{C}(12)-\mathrm{H}(13)$ & $\delta 35$ & $\mathrm{H}(10)-\mathrm{C}(5)-\mathrm{C}(6)$ & $\tau 63$ & $\mathrm{H}(13)-\mathrm{C}(12)-\mathrm{S}(15)-\mathrm{S}(16)$ \\
\hline$v 7$ & $\mathrm{C}(12)-\mathrm{H}(14)$ & $\delta 36$ & $\mathrm{H}(11)-\mathrm{C}(6)-\mathrm{C}(1)$ & $\tau 64$ & $\mathrm{H}(14)-\mathrm{C}(12)-\mathrm{S}(15)-\mathrm{S}(16)$ \\
\hline$v 8$ & $\mathrm{C}(17)-\mathrm{H}(18)$ & $\delta 37$ & $\mathrm{H}(13)-\mathrm{C}(12)-\mathrm{S}(15)$ & $\tau 65$ & $\mathrm{H}(18)-\mathrm{C}(17)-\mathrm{S}(16)-\mathrm{S}(15)$ \\
\hline$v 9$ & $\mathrm{C}(17)-\mathrm{H}(19)$ & $\delta 38$ & $\mathrm{H}(14)-\mathrm{C}(12)-\mathrm{H}(13)$ & $\tau 66$ & $\mathrm{H}(19)-\mathrm{C}(17)-\mathrm{S}(16)-\mathrm{S}(15)$ \\
\hline$v 10$ & $\mathrm{C}(21)-\mathrm{H}(24)$ & $\delta 39$ & $\mathrm{H}(18)-\mathrm{C}(17)-\mathrm{S}(16)$ & $\tau 67$ & $\mathrm{H}(24)-\mathrm{C}(21)-\mathrm{C}(23)-\mathrm{C}(27)$ \\
\hline$v 11$ & $\mathrm{C}(22)-\mathrm{H}(26)$ & $\delta 40$ & $\mathrm{H}(19)-\mathrm{C}(17)-\mathrm{H}(18)$ & $\tau 68$ & $\mathrm{H}(26)-\mathrm{C}(22)-\mathrm{C}(25)-\mathrm{C}(27)$ \\
\hline$v 12$ & $\mathrm{C}(23)-\mathrm{H}(28)$ & $\delta 41$ & $\mathrm{H}(24)-\mathrm{C}(21)-\mathrm{C}(23)$ & $\tau 69$ & $\mathrm{H}(28)-\mathrm{C}(23)-\mathrm{C}(27)-\mathrm{C}(25)$ \\
\hline$v 13$ & $\mathrm{C}(25)-\mathrm{H}(29)$ & $\delta 42$ & $\mathrm{H}(26)-\mathrm{C}(22)-\mathrm{C}(25)$ & $\tau 70$ & $\mathrm{H}(29)-\mathrm{C}(25)-\mathrm{C}(27)-\mathrm{C}(23)$ \\
\hline$v 14$ & $\mathrm{C}(27)-\mathrm{H}(30)$ & $\delta 43$ & $\mathrm{H}(28)-\mathrm{C}(23)-\mathrm{C}(27)$ & $\tau 71$ & $\mathrm{H}(30)-\mathrm{C}(27)-\mathrm{C}(25)-\mathrm{C}(22)$ \\
\hline$v 15$ & $\mathrm{C}(2)-\mathrm{C}(1)$ & $\delta 44$ & $\mathrm{H}(29)-\mathrm{C}(25)-\mathrm{C}(27)$ & $\tau 72$ & $C(2)-C(1)-C(6)-C(5)$ \\
\hline$v 16$ & $C(22)-C(25)$ & $\delta 45$ & $\mathrm{H}(30)-\mathrm{C}(27)-\mathrm{C}(25)$ & $\tau 73$ & $C(22)-C(25)-C(27)-C(23)$ \\
\hline$v 17$ & $C(1)-C(6)$ & $\delta 46$ & $C(2)-C(1)-C(6)$ & $\tau 74$ & $C(1)-C(6)-C(5)-C(4)$ \\
\hline$v 18$ & $C(5)-C(6)$ & $\delta 47$ & $C(1)-C(6)-C(5)$ & $\tau 75$ & $C(6)-C(5)-C(4)-C(3)$ \\
\hline$v 19$ & $C(27)-C(23)$ & $\delta 48$ & $C(6)-C(5)-C(4)$ & $\tau 76$ & $\mathrm{C}(4)-\mathrm{C}(3)-\mathrm{C}(12)-\mathrm{C}(15)$ \\
\hline$v 20$ & $\mathrm{C}(4)-\mathrm{C}(3)$ & $\delta 49$ & $C(4)-C(3)-C(12)$ & $\tau 77$ & $C(5)-C(4)-C 3)-C(12)$ \\
\hline$v 21$ & $C(5)-C(4)$ & $\delta 50$ & $C(5)-C(4)-C(3)$ & $\tau 78$ & $C(20)-C(21)-C(23)-C(27)$ \\
\hline$v 22$ & $C(20)-C(21)$ & $\delta 51$ & $C(20)-C(21)-C(23)$ & $\tau 79$ & $C(25)-C(27)-C(23)-C(21)$ \\
\hline$v 23$ & $C(21)-C(23)$ & $\delta 52$ & $C(21)-C(23)-C(27)$ & $\tau 80$ & $C(3)-C(12)-S(15)-S(16)$ \\
\hline$v 24$ & $C(25)-C(27)$ & $\delta 53$ & $\mathrm{C}(25)-\mathrm{C}(27)-\mathrm{C}(23)$ & $\tau 81$ & $C(12)-S(15)-S(16)-C(17)$ \\
\hline$v 25$ & $C(3)-C(12)$ & 854 & $C(17)-C(20)-C(22)$ & $\tau 82$ & $S(16)-C(17)-C(20)-C(21)$ \\
\hline$v 26$ & $C(17)-C(20)$ & $\delta 55$ & $C(12)-S(15)-S(16)$ & $\tau 83$ & $S(15)-S(16)-C(17)-C(20)$ \\
\hline$v 27$ & $S(15)-C(12)$ & $\delta 56$ & $S(16)-C(17)-C(20)$ & $\gamma 84$ & $C(17)-C(21)-C(22)-C(20)$ \\
\hline$v 28$ & $S(16)-C(17)$ & $\delta 57$ & $S(15)-S(16)-C(17)$ & & \\
\hline$v 29$ & $S(15)-S(16)$ & & & & \\
\hline
\end{tabular}

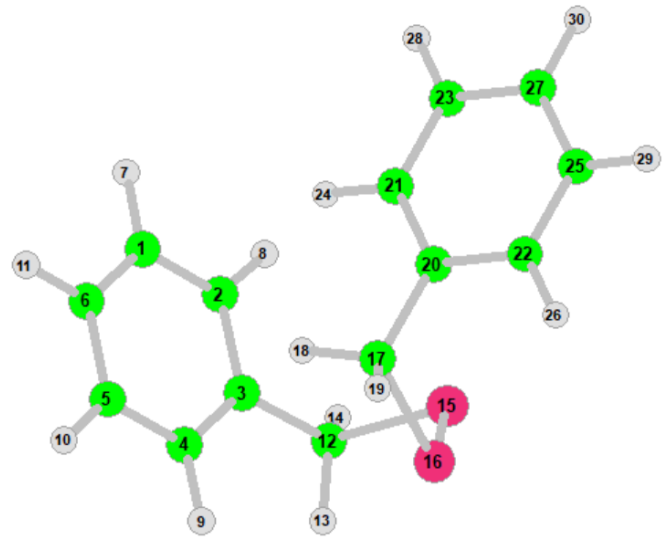

Figure 4. The atomic number of DBDS in VEDA4.

The internal coordinates of DBDS-1 conformation consist of 29 kinds of stretching, 28 kinds of bending, and 27 kinds of torsion. The contribution of different internal coordinates to the normal vibration mode is shown in Tables 3 and 4 . Similarly, the detailed table of other conformations is provided in Supplementary Material. It should be noted that the internal coordinates contribution less than $10 \%$ are ignored. The normal modes of DBDS-1 are divided into low frequency $\left(<400 \mathrm{~cm}^{-1}\right)$, middle frequency $\left(400 \sim 2800 \mathrm{~cm}^{-1}\right)$, and high frequency $\left(>2800 \mathrm{~cm}^{-1}\right)$. The scaled frequency was corrected by a factor of 0.9640 [41]. 
Table 3. Assignment of high frequency normal mode of DBDS-1.

\begin{tabular}{ccl}
\hline Normal Mode & Scaled Frequency $\left(\mathbf{c m}^{-\mathbf{1}}\right)$ & Vibration Assignment $(>\mathbf{1 0} \%)$ \\
\hline$\# 1$ & 3077.87 & $\% 14 v(1)+\% 11 v(3)+\% 25 v(4)+\% 34 v(5)$ \\
$\# 2$ & 3077.32 & $\% 40 v(10)+\% 20 v(12)+\% 16 v(14)$ \\
$\# 3$ & 3071.02 & $\% 38 v(10)+\% 31 v(13)+\% 24 v(14)$ \\
$\# 4$ & 3068.73 & $\% 27 v(1)+\% 41 v(3)+\% 15 v(4)$ \\
$\# 5$ & 3061.73 & $\% 23 v(1)+\% 22 v(2)+\% 24 v(3)+\% 23 v(5)$ \\
$\# 6$ & 3061.38 & $\% 23 v(11)+\% 22 v(12)+\% 25 v(13)+\% 21 v(14)$ \\
$\# 7$ & 3053.17 & $\% 22 v(2)+\% 20 v(3)+\% 42 v(4)+\% 16 v(5)$ \\
$\# 8$ & 3051.51 & $\% 36 v(11)+\% 40 v(12)+\% 14 v(14)$ \\
$\# 9$ & 3046.70 & $\% 33 v(1)+\% 47 v(2)+\% 12 v(5)$ \\
$\# 10$ & 3045.33 & $\% 33 v(11)+\% 14 v(12)+\% 30 v(13)+\% 21 v(14)$ \\
$\# 11$ & 3024.71 & $\% 88 v(8)+\% 11 v(9)$ \\
$\# 12$ & 3007.35 & $\% 77 v(6)+\% 23 v(7)$ \\
$\# 13$ & 2946.40 & $\% 22 v(6)+\% 77 v(7)$ \\
$\# 14$ & 2942.76 & $\% 11 v(8)+\% 88 v(9)$ \\
\hline
\end{tabular}

Table 4. Assignment of middle frequency normal mode of DBDS-1.

\begin{tabular}{|c|c|c|}
\hline Normal Mode & Scaled Frequency $\left(\mathrm{cm}^{-1}\right)$ & Vibration Assignment (>10\%) \\
\hline$\# 15$ & 1590.90 & $\% 30 v(16)+\% 10 v(19)$ \\
\hline \#16 & 1588.63 & $\% 30 v(15)+\% 11 v(18)$ \\
\hline \#17 & 1571.78 & $\% 28 v(19)+\% 21 v(22)$ \\
\hline$\# 18$ & 1569.58 & $\% 27 v(18)+\% 23 v(20)$ \\
\hline \#19 & 1476.26 & $\% 16 \delta(41)+\% 15 \delta(42)+\% 16 \delta(43)+\% 18 \delta(44)$ \\
\hline$\# 20$ & 1474.92 & $\% 19 \delta(32)+\% 15 \delta(33)+\% 15 \delta(34)+\% 16 \delta(35)$ \\
\hline \#21 & 1437.59 & $\% 11 \delta(40)+\% 20 \delta(45)$ \\
\hline \#22 & 1434.55 & $\% 10 v(21)+\% 10 \delta(35)+\% 24 \delta(36)$ \\
\hline$\# 23$ & 1420.17 & $\% 53 \delta(40)+\% 12 \tau(66)$ \\
\hline \#24 & 1415.30 & $\% 60 \delta(38)+\% 12 \tau(63)+\% 16 \tau(64)$ \\
\hline$\# 25$ & 1313.79 & $\% 27 \delta(41)+\% 24 \delta(42)+\% 11 \delta(44)+\% 10 \delta(45)$ \\
\hline \#26 & 1311.88 & $\% 11 \delta(32)+\% 25 \delta(33)+\% 26 \delta(34)+\% 10 \delta(35)+\% 10 \delta(36)$ \\
\hline \#27 & 1296.69 & $\% 20 v(16)+\% 22 v(22)+\% 17 v(23)+\% 16 v(24)$ \\
\hline \#28 & 1295.12 & $\% 18 v(15)+\% 17 v(17)+\% 24 v(20)+\% 16 v(21)$ \\
\hline \#29 & 1225.70 & $\% 12 \delta(39)+\% 18 \delta(40)+\% 12 \tau(65)+\% 16 \tau(66)$ \\
\hline$\# 30$ & 1220.57 & $\% 20 \delta(38)+\% 11 \tau(63)+\% 14 \tau(64)$ \\
\hline \#31 & 1190.12 & $\% 22 v(25)+\% 14 v(26)$ \\
\hline \#32 & 1188.81 & $\% 12 v(25)+\% 22 v(26)$ \\
\hline \#33 & 1162.78 & $\% 15 \delta(41)+\% 16 \delta(42)+\% 14 \delta(43)+\% 11 \delta(44)$ \\
\hline \#34 & 1160.99 & $\% 13 \delta(32)+\% 16 \delta(33)+\% 15 \delta(34)+\% 13 \delta(35)$ \\
\hline \#35 & 1141.18 & $\% 18 \delta(32)+\% 19 \delta(35)+\% 38 \delta(36)$ \\
\hline \#36 & 1140.39 & $\% 19 \delta(43)+\% 19 \delta(44)+\% 37 \delta(45)$ \\
\hline \#37 & 1126.57 & $\% 33 \delta(39)+\% 10 \tau(65)+\% 34 \tau(66)$ \\
\hline \#38 & 1123.89 & $\% 35 \delta(37)+\% 10 \tau(63)+\% 31 \tau(64)$ \\
\hline \#39 & 1062.59 & $\% 13 v(16)+\% 15 v(23)+\% 10 \delta(39)+\% 10 \delta(42)+\% 13 \delta(45)$ \\
\hline$\# 40$ & 1060.74 & $\% 13 v(15)+\% 15 v(21)+\% 12 \delta(36)+\% 11 \delta(37)$ \\
\hline \#41 & 1015.83 & $\% 19 v(19)+\% 24 v(24)+\% 13 \delta(30)+\% 11 \delta(43)+\% 10 \delta(44)$ \\
\hline \#42 & 1014.97 & $\% 24 v(17)+\% 21 v(18)+\% 11 \delta(35)+\% 15 \delta(46)$ \\
\hline$\# 43$ & 985.97 & $\% 10 v(19)+\% 11 v(24)+\% 26 \delta(30)+\% 13 \delta(52)+\% 18 \delta(53)$ \\
\hline$\# 44$ & 985.52 & $\% 11 v(17)+\% 10 v(18)+\% 25 \delta(46)+\% 19 \delta(47)+\% 13 \delta(48)$ \\
\hline \#45 & 967.00 & $\% 22 \tau(58)+\% 15 \tau(61)+\% 26 \tau(62)+\% 16 \tau(72)$ \\
\hline \#46 & 964.61 & $\% 20 \tau(69)+\% 18 \tau(70)+\% 30 \tau(71)+\% 10 \tau(73)$ \\
\hline \#47 & 948.26 & $\% 17 \tau(58)+\% 16 \tau(59)+\% 15 \tau(60)+\% 26 \tau(61)$ \\
\hline \#48 & 943.31 & $\% 19 \tau(67)+\% 17 \tau(68)+\% 23 \tau(69)+\% 26 \tau(70)$ \\
\hline \#49 & 897.82 & $\% 21 \tau(67)+\% 19 \tau(68)+\% 24 \tau(71)$ \\
\hline$\# 50$ & 894.49 & $\% 20 \tau(59)+\% 23 \tau(60)+\% 24 \tau(62)$ \\
\hline \#51 & 864.65 & $\% 14 \delta(39)+\% 11 \tau(63)+\% 20 \tau(65)$ \\
\hline \#52 & 862.53 & $\% 17 \delta(37)+\% 20 \tau(63)+\% 11 \tau(65)$ \\
\hline$\# 53$ & 826.45 & $\% 22 \tau(58)+\% 22 \tau(59)+\% 23 \tau(60)+\% 20 \tau(61)$ \\
\hline
\end{tabular}


Table 4. Cont.

\begin{tabular}{ccl}
\hline Normal Mode & Scaled Frequency $\left(\mathbf{c m}^{-\mathbf{1}} \mathbf{)}\right.$ & Vibration Assignment $(\mathbf{> 1 0} \%)$ \\
\hline$\# 54$ & 823.51 & $\% 21 \tau(67)+\% 24 \tau(68)+\% 21 \tau(69)+\% 21 \tau(70)$ \\
$\# 55$ & 797.93 & $\% 19 v(26)+\% 10 \delta(52)+\% 30 \delta(53)$ \\
$\# 56$ & 794.54 & $\% 18 v(25)+\% 30 \delta(47)$ \\
$\# 57$ & 750.92 & $\% 17 \tau(58)+\% 15 \tau(61)+\% 14 \tau(62)+\% 21 \tau(75)$ \\
$\# 58$ & 745.18 & $\% 14 \tau(69)+\% 13 \tau(70)+\% 11 \tau(71)+\% 20 \tau(78)+\% 13 \gamma(84)$ \\
$\# 59$ & 687.46 & $\% 10 \tau(59)+\% 10 \tau(60)+\% 15 \tau(62)+\% 10 \tau(72)+\% 19 \tau(75)$ \\
$\# 60$ & 685.91 & $\% 10 \tau(68)+\% 14 \tau(71)+\% 25 \tau(78)$ \\
$\# 61$ & 634.47 & $\% 50 v(27)$ \\
$\# 62$ & 628.24 & $\% 41 v(28)$ \\
$\# 63$ & 614.53 & $\% 23 \delta(46)+\% 33 \delta(48)+\% 19 \delta(50)$ \\
$\# 64$ & 613.15 & $\% 13 v(28)+\% 20 \delta(30)+\% 27 \delta(52)$ \\
$\# 65$ & 558.03 & $\% 20 \delta(51)+\% 14 \delta(56)$ \\
$\# 66$ & 551.85 & $\% 16 \delta(31)+\% 19 \delta(50)$ \\
$\# 67$ & 468.56 & $\% 11 v(27)+\% 17 v(29)+\% 22 \tau(74)$ \\
$\# 68$ & 462.98 & $\% 30 v(29)+\% 14 \gamma(84)$ \\
$\# 69$ & 454.94 & $\% 51 v(29)$ \\
\hline
\end{tabular}

Modes \#1 \#14 are high frequency normal modes. All of them are contributed by stretching vibration, and there is a large frequency gap between \#14 and \#15. They have completely different characteristics in the frequency band. This is because the force constant of the stretching vibration is larger. The stretching vibration energy is greater than bending and torsion vibration energy. Therefore, the characteristic frequencies corresponding to the stretching vibration are all located in the high frequency region. Generally, almost all molecules have abundant vibration peaks corresponding to stretching vibrations in the high frequency region. The main feature of the low frequency zone is that no stretching contribution is assigned, while the middle frequency area is composed of various vibration contributions. The spectrum characteristics in the low frequency region is ignored in the following analysis. As the measurement range of FTIR only covers $400-4000 \mathrm{~cm}^{-1}$, and the range of Raman spectroscopy in the low frequency zone is seriously affected by Rayleigh scattering.

The normal modes always appear in pairs. This is because DBDS is a quasi-symmetric molecule. Although the DBDS-1 conformation does not have molecular symmetry, its molecular composition is still symmetrical. For example, the vibration mode of one benzene ring must have the corresponding vibration mode of another benzene ring.

\subsubsection{Methylene(- $\left.\mathrm{CH}_{2}\right)$ Group}

In the high frequency zone, the asymmetric stretching vibration of the two - $\mathrm{CH} 2$ groups corresponds to the \#11 and \#12 normal modes. The two mode peaks appear at $3007 \mathrm{~cm}^{-1}$ and $3025 \mathrm{~cm}^{-1}$ respectively, due to the vibration coupling (the calculated Raman and IR spectra are shown in Figures S4 and S5, respectively). The infrared activity of \#12 mode is weak, almost invisible, in the IR spectrum. The symmetric stretching vibration of the two - $\mathrm{CH} 2$ groups corresponds to the \#13 and \#14 normal modes. These two modes appear as the same peak at $2946 \mathrm{~cm}^{-1}$. The frequency of -CH2 symmetrical vibration is often smaller than that of asymmetrical vibration [21].

In the middle frequency zone, the scissoring vibration of - $\mathrm{CH} 2$ appears at $1416 \mathrm{~cm}^{-1}$, corresponding to mode $\# 23$ and $\# 24$. When wagging vibration of $-\mathrm{CH} 2$ appears at $1223 \mathrm{~cm}^{-1}$, corresponding to mode \#29 and \#30. High Raman activity and infrared activity are simultaneously exhibited in wagging vibration. The twisting vibration of - $\mathrm{CH} 2$ corresponds to $\# 37$ and \#38 at $1126 \mathrm{~cm}^{-1}$. The rocking vibration of $-\mathrm{CH} 2$ corresponds to \#51 and \#52 at $863 \mathrm{~cm}^{-1}$. The activity of these four modes is relatively weak.

For the $-\mathrm{CH} 2$ group, the order of normal vibration frequency from large to small is: asymmetric stretch, symmetric stretch, scissoring, wagging, twisting, and rocking. 


\subsubsection{Phenyl $\left(-\mathrm{C}_{5} \mathrm{H}_{6}\right)$ Group}

In the high frequency zone, the \#1 and \#2 normal modes correspond to the in-phase stretching vibration of the $\mathrm{C}-\mathrm{H}$ bond on the benzene ring. For both \#1 and \#2 modes, the five $\mathrm{C}-\mathrm{H}$ bonds on the benzene ring will vibrate in the synchronous phase. Two modes appear as the same peak at $3077 \mathrm{~cm}^{-1}$. This characteristic peak is the strongest peak in the Raman spectrum, but not in the infrared spectrum. The eight \#3 \#10 normal modes correspond to the asynchronous phase vibration of the $\mathrm{C}-\mathrm{H}$ bonds on the benzene ring, and the Raman activity and infrared activity of these eight modes are quite different. Modes \#3 and \#4 appear at $3069 \mathrm{~cm}^{-1}$ in the IR spectrum. Modes \#5 and \#6 appear at $3062 \mathrm{~cm}^{-1}$ in both the IR and Raman spectrum. Modes \#7 and \#8 appear as a peak at $3051 \mathrm{~cm}^{-1}$ in the Raman spectrum.

In the middle frequency zone, the stretching vibration of the carbon skeleton of the benzene ring corresponds to modes \#15 \#18, \#27, and \#28. The frequency of these stretching vibration modes is much smaller than the $\mathrm{C}-\mathrm{H}$ bond stretching vibration. This shows that the vibration force constant of the carbon skeleton is much smaller than the force constant of the $\mathrm{C}-\mathrm{H}$ bond. The bending vibration of the hydrogen atoms on the benzene ring corresponds to \#19 \#22, \#25,\#26, \#33 \#36, \#39, and \#40. Modes \#31 and \#32 have very strong coupling characteristics. All atoms except disulfide bonds are involved, and both apparent carbon skeleton stretching and hydrogen atoms bending occurred.

The \#41 mode (frequency $<1016 \mathrm{~cm}^{-1}$ ) began to exhibit bending of the benzene ring carbon skeleton The bending and stretching vibrations of the carbon skeleton of the benzene ring simultaneously appear in the \#41 and \#42 modes. The \#43, \#44, \#55, \#56, and \#63 \#66 modes correspond to bending vibration of benzene ring carbon skeleton. High Raman activity is exhibited in these two modes, appearing as peak at $986 \mathrm{~cm}^{-1}$, which is also the characteristic peak used for Raman spectroscopy based DBDS detection in our study in progress.

From the $\# 45$ mode (frequency $<967 \mathrm{~cm}^{-1}$ ), the out-of-plane bending of hydrogen atoms on benzene ring occurs. Modes \#45 \#50, \#53 and \#54, and \#57 \#60 correspond to this type of vibration. Modes \#67 \#69 correspond to the deformation vibration of the benzene ring couple with the stretching vibration of disulfide bond. The other out-of-plane vibration of the benzene ring appeared in the low frequency zone.

The \#61 and \#62 modes are composed of multiple vibrations, mainly including the in-plane bending, out-of-plane bending of the benzene ring, and the stretching vibration of C-S bond.

\subsection{Weighted Vibrational Spectra}

Different conformations have their own vibrational spectra. The weighed spectrum was calculated by different weighted conformations spectra according to their proportion. Frequency calculation is carried out in the optimal conformations; there is no imaginary frequency observed in the result. A frequency correction factor (0.9640) for B3LYP/6$311 \mathrm{G}^{* *}$ [41] was applied to the vibration spectra of DBDS, DBS, and BiBz due to the overestimated frequency of anharmonic effect.

Take the Raman spectra of DBDS as an example to illustrate the role of weighted spectrum. Figure 5 shows the Raman spectra of two DBDS conformations in the high frequency zone. The most significant difference between the two conformations is that DBDS-1 has a characteristic peak at $3025 \mathrm{~cm}^{-1}$, but DBDS-2 has a characteristic peak at $2970 \mathrm{~cm}^{-1}$.

Based on the vibration assignment in Section 4.1, the peak at $3025 \mathrm{~cm}^{-1}$ is assigned to asymmetrical stretching vibration of two $-\mathrm{CH}_{2}$ groups in DBDS-1. The peak at $2970 \mathrm{~cm}^{-1}$ is assigned to symmetric stretching of $-\mathrm{CH}_{2}$ group in DBDS-2. The Raman spectra of different conformations are different, but they are all superimposed in the weighted curve, as shown in Figure 5's blue line. The vibration spectroscopy is revealed much better when based on conformation weighted curve. 


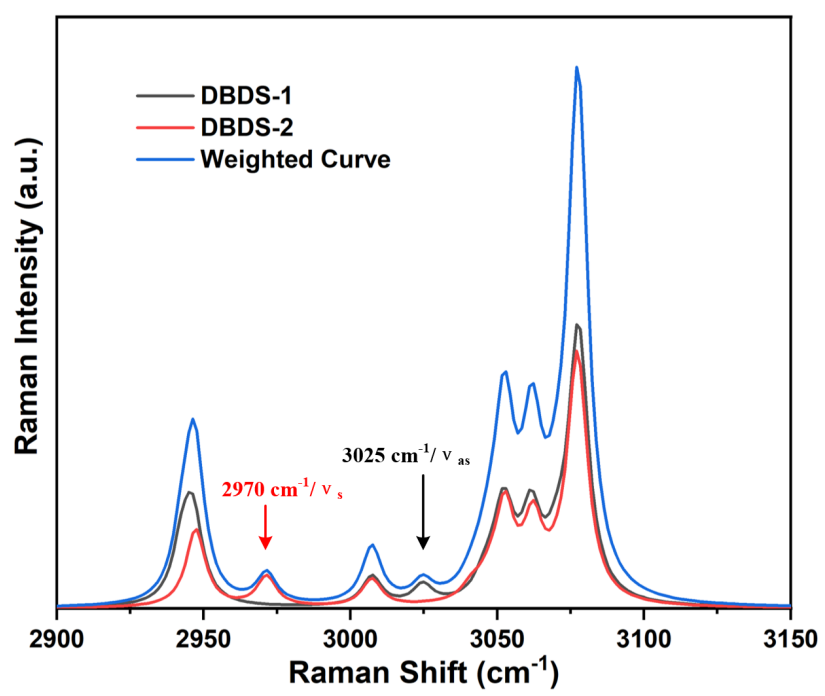

Figure 5. Theoretically calculated conformations Raman spectra and weighted curve of DBDS.

It should be noted that the Raman spectrum obtained by theoretical calculation is a spectrum of Raman activity (unit in $\AA^{4} / \mathrm{amu}$ ). In order to compare with the experimental spectrum, the Raman activity is converted into the Raman intensity, depending on the frequency of incident light and ambient temperature [42]:

$$
\begin{gathered}
I_{i}=\frac{C\left(v_{o}-v_{i}\right)^{4} S_{i}}{v_{i} B_{i}} \\
B_{i}=1-\exp \left(-\frac{h c v_{i}}{k T}\right)
\end{gathered}
$$

where $S_{i}, I_{i}$, and $v_{i}$ are the Raman activity, Raman intensity, and vibration frequency of $i$ th vibration mode respectively. $v_{0}$ is the frequency of incident light. $T$ is the ambient temperature, $h$ is Planck's constant, $c$ is the speed of light, $k$ is Boltzmann's constant, and $C$ is an arbitrary constant. The conversion process above was conducted via Multiwfn code [38]. The laser source wavelength used in our experimental platform is $532 \mathrm{~nm}$, and room temperature was set as $298.15 \mathrm{~K}$.

\subsection{Comparison of Theoretical and Experimental Spectra}

The experimentally measured and theoretically calculated spectra of DBDS, DBS, and $\mathrm{BiBz}$ are provided in Supplementary Material. It can be found from the Figures S4-S9 that the experimental Raman spectrum is in good agreement with the theoretical spectrum. Generally, the B3LYP hybrid functional combining with 6-311G ${ }^{* *}$ basis set overestimates the vibrational frequency in the high vibrational frequency zone but underestimates the frequency in the low frequency zone. This phenomenon is consistent with previous studies [43]. Dual scaling factor in the high frequency zone and low frequency zone is optional for agreement improvement.

In order to quantitatively describe the consistency between the theoretical spectrum and the experimental spectrum, a linear fitting operation is performed to each characteristic peak of DBDS. The abscissa of peak data is the experimental frequency, and the ordinate is the theoretical frequency. The peak data fitting line close to $y=x$ indicates a better agreement between the experimental value and the theoretical value. As shown in Figure 6, the fitting lines of Raman spectrum and infrared spectrum both show good linearity. The goodness of fit reaches 0.99979 and 0.99981, respectively. A good agreement is revealed at B3LYP-D3(BJ)/6-311G** level as the slope of the fitted line is close to 1. 

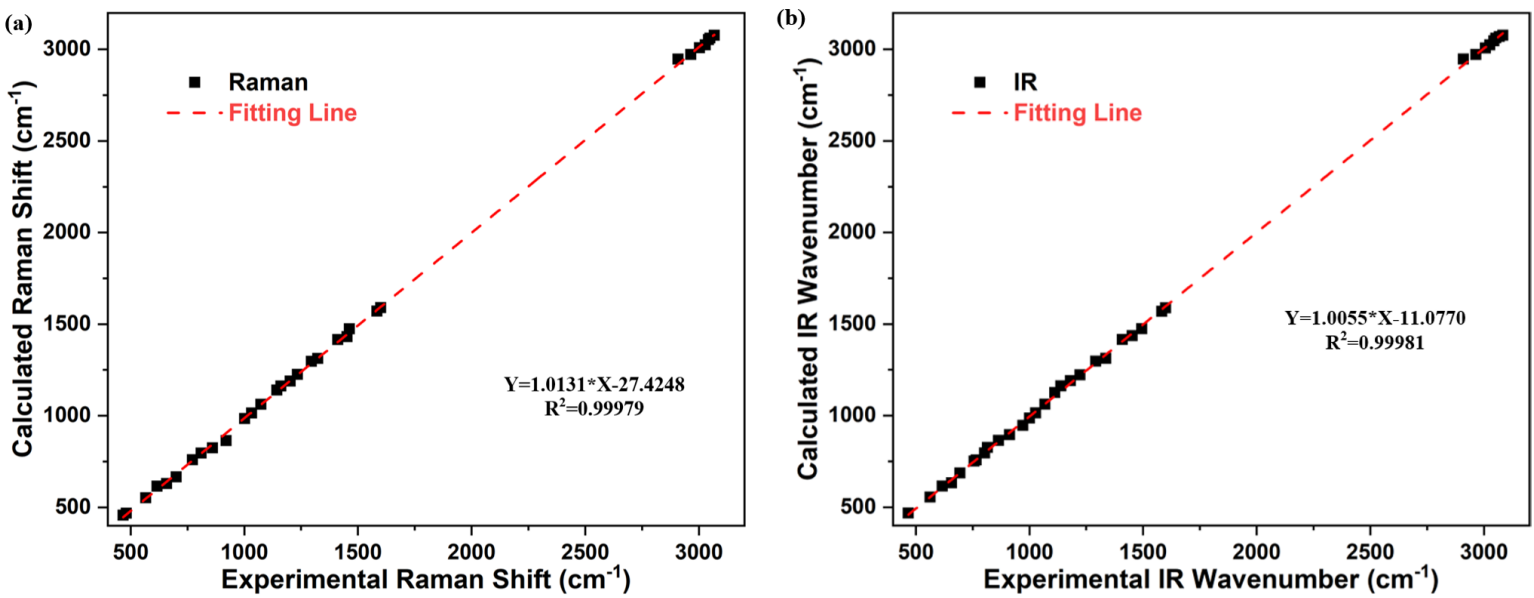

Figure 6. Linear fitting between theoretical and experimental Raman shift.

The mode identification is shown in Tables 5 and 6. Most experimental Raman peaks can be identified to corresponding normal modes within a reasonable deviation. There are also some normal vibration modes which are not measured in the experimental spectrum due to the weak Raman activity or infrared activity.

Table 5. Comparison of experimental and theoretical Raman spectrum.

\begin{tabular}{|c|c|c|c|}
\hline Experimental Raman Peak $\left(\mathrm{cm}^{-1}\right)$ & Corresponding Calculated Peak $\left(\mathrm{cm}^{-1}\right)$ & Mode Identification & Deviation $\left(\mathrm{cm}^{-1}\right)$ \\
\hline 467 & 456 & \#69 & 11 \\
\hline 481 & 467 & $\# 67+\# 68$ & 14 \\
\hline 504 & - & $\begin{array}{l}\text { Overtone of low frequency } \\
\text { vibration }\end{array}$ & - \\
\hline 567 & 552 & $\# 65+\# 66$ & 15 \\
\hline 616 & 615 & $\# 63+\# 64$ & 1 \\
\hline 659 & 630 & $\# 61+\# 62$ (DBDS-1) & 29 \\
\hline 701 & 666 & \#61 + \#62 (DBDS-2) & 35 \\
\hline 772 & 760 & \#57 (DBDS-2) & 12 \\
\hline 811 & 796 & $\# 55+\# 56$ & 15 \\
\hline 860 & 824 & $\# 53+\# 54$ & 36 \\
\hline 920 & 864 & $\# 51+\# 52$ & 56 \\
\hline 1002 & 985 & $\# 43+\# 44$ & 17 \\
\hline 1033 & 1015 & $\# 41+\# 42$ & 18 \\
\hline 1074 & 1062 & $\# 39+\# 40$ & 12 \\
\hline- & 1125 & $\# 37+\# 38$ & - \\
\hline 1143 & 1140 & $\# 35+\# 36$ & 3 \\
\hline 1162 & 1162 & $\# 33+\# 34$ & 0 \\
\hline 1202 & 1189 & $\# 31+\# 32$ & 13 \\
\hline 1234 & 1225 & $\# 29+\# 30$ & 9 \\
\hline 1295 & 1296 & $\# 27+\# 28$ & -1 \\
\hline 1324 & 1312 & $\# 25+\# 26$ & 12 \\
\hline 1338 & - & Double frequency band of 659 & - \\
\hline 1411 & 1416 & $\# 23+\# 24$ & -5 \\
\hline 1452 & 1432 & $\# 21+\# 22$ & 20 \\
\hline 1463 & 1475 & $\# 19+\# 20$ & -12 \\
\hline 1495 & - & $\begin{array}{l}\text { Combination of } 1002 \text { and } 481 \\
\text { under Fermi resonance }\end{array}$ & - \\
\hline 1526 & - & $\begin{array}{l}\text { Combination of } 1002 \text { and } 481 \\
\text { under Fermi resonance }\end{array}$ & - \\
\hline 1584 & 1571 & $\# 17+\# 18$ & 13 \\
\hline 1600 & 1590 & $\# 15+\# 16$ & 10 \\
\hline 2908 & 2946 & $\# 13$ + \#14(DBDS-1) & -38 \\
\hline 2964 & 2972 & $\# 13$ (DBDS-2) & -8 \\
\hline 3002 & 3008 & $\# 12$ & -6 \\
\hline 3028 & 3025 & \#11 (DBDS-1) & 3 \\
\hline 3042 & 3053 & $\# 7+\# 8$ & -11 \\
\hline 3049 & 3062 & $\# 5+\# 6$ & -13 \\
\hline 3068 & 3077 & $\# 1+\# 2$ & -9 \\
\hline
\end{tabular}


Table 6. Comparison of experimental and theoretical IR spectrum.

\begin{tabular}{|c|c|c|c|}
\hline Experimental IR Peak $\left(\mathrm{cm}^{-1}\right)$ & Corresponding Calculated Peak $\left(\mathrm{cm}^{-1}\right)$ & Mode Identification & Deviation $\left(\mathrm{cm}^{-1}\right)$ \\
\hline 467 & 467 & $\# 67+\# 68$ & 0 \\
\hline 505 & - & $\begin{array}{l}\text { Overtone of low frequency } \\
\text { vibration }\end{array}$ & - \\
\hline 563 & 555 & $\# 65+\# 66$ & 8 \\
\hline 569 & - & $\begin{array}{l}\text { Overtone of low frequency } \\
\text { vibration }\end{array}$ & - \\
\hline 617 & 615 & $\# 63+\# 64$ & 2 \\
\hline 658 & 633 & $\# 61+\# 62$ & 25 \\
\hline 695 & 687 & $\# 59+\# 60$ & 8 \\
\hline 757 & 751 & \#57 + \#58 (DBDS-1) & 6 \\
\hline 766 & 758 & \#57 (DBDS-2) & 8 \\
\hline 803 & 796 & $\# 55+\# 56$ & 7 \\
\hline 816 & 826 & $\# 53+\# 54$ & -10 \\
\hline 864 & 864 & $\# 51+\# 52$ & 0 \\
\hline 912 & 895 & $\# 49+\# 50$ & 17 \\
\hline 971 & 947 & $\# 47+\# 48$ & 24 \\
\hline 1001 & 986 & $\# 43+\# 44$ & 15 \\
\hline 1028 & 1015 & $\# 41+\# 42$ & 13 \\
\hline 1068 & 1062 & $\# 39+\# 40$ & 6 \\
\hline 1112 & 1126 & $\# 37+\# 38$ & -14 \\
\hline 1139 & 1162 & $\# 33+\# 34$ & -23 \\
\hline 1181 & 1190 & $\# 31+\# 32$ & -9 \\
\hline 1198 & - & Combination of 695 and 563 & - \\
\hline 1223 & 1223 & $\# 29+\# 30$ & 0 \\
\hline 1291 & 1296 & $\# 27+\# 28$ & -5 \\
\hline 1336 & 1313 & $\# 25+\# 26$ & 23 \\
\hline 1409 & 1416 & $\# 23+\# 24$ & -7 \\
\hline 1452 & 1436 & $\# 21+\# 22$ & 16 \\
\hline 1494 & 1475 & $\# 19+\# 20$ & 19 \\
\hline 1582 & 1570 & $\# 17+\# 18$ & 12 \\
\hline 1599 & 1588 & $\# 15+\# 16$ & 11 \\
\hline 2909 & 2946 & $\# 13$ + \#14 (DBDS-1) & -37 \\
\hline 2964 & 2972 & \#13 (DBDS-2) & -8 \\
\hline 3006 & 3007 & $\# 12$ & -1 \\
\hline 3026 & 3025 & \#11 (DBDS-1) & 1 \\
\hline 3043 & 3047 & $\# 9+\# 10$ & -4 \\
\hline 3052 & 3062 & $\# 5+\# 6$ & -10 \\
\hline 3068 & 3070 & $\# 3+\# 4$ & -2 \\
\hline 3083 & 3077 & $\# 1+\# 2$ & 6 \\
\hline
\end{tabular}

Different conformations contribute to different experimental peaks. For example, in the both Raman and infrared experimental spectra, the peak at $2964 \mathrm{~cm}^{-1}$ is only generated by the \#13 normal mode of DBDS-2, while the \#13 normal mode of DBDS-1 contribute to the peak at $2908 \mathrm{~cm}^{-1}$ together with the $\# 14$ mode. The characteristic peaks generated by a single conformation are marked with parentheses in Tables 5 and 6 .

In addition to the fundamental frequency band in the vibrational spectroscopy, there are many anharmonic phenomenon such as overtone, combination band, Fermi resonance, etc. Which contribute to several characteristic peaks in experiment spectrum that are not observed in the theoretical spectrum. For example, two peaks are observed in experimental Raman spectrum at $1495 \mathrm{~cm}^{-1}$ and $1526 \mathrm{~cm}^{-1}$. While the adjacent peaks at $1463 \mathrm{~cm}^{-1}$ and $1584 \mathrm{~cm}^{-1}$ correspond to the $\# 19, \# 20, \# 17$, and \#18 mode, respectively. There is no corresponding theoretical normal mode for these two peaks (1495 and 1526) assignment. They are actually a combination band of peaks at $1002 \mathrm{~cm}^{-1}$ and $481 \mathrm{~cm}^{-1}$. The peak at $1002 \mathrm{~cm}^{-1}$ (\#43+\#44) corresponds to in-plane bending vibration of benzene ring carbon skeleton, while the peak at $481 \mathrm{~cm}^{-1}(\# 67+\# 68)$ is corresponding to the out-of-plane deformation vibration of the benzene ring. This kind of highly correlated vibration is prone to coupling and generating combined frequency band. Fermi resonance most often occurs between fundamental and overtone (combination) excitations, if they are nearly coincident in energy. The two peaks (1495 and 1526) are thus split under Fermi resonance with the action of strong fundamental frequency band $\left(1600 \mathrm{~cm}^{-1}\right)$. 


\subsection{Comparison of $D B D S, D B S$, and $B i B z$}

DBDS, DBS, and Bibz have remarkable similarities in molecular structure. The only difference is the number of sulfur atoms between the two benzyl groups. The electronegativity of sulfur atoms is stronger than that of carbon atoms and hydrogen atoms. The sulfur atom will cause the redistribution of electron as discussed in Section 3.1, which changes the molecular vibration frequency. The spectra comparison of DBDS, DBS, and BiBz is shown in Figure 7. In order to reveal the similarity and difference of the vibrational behaviors of the three molecules, the six vibrational behaviors of the methylene groups is analyzed.
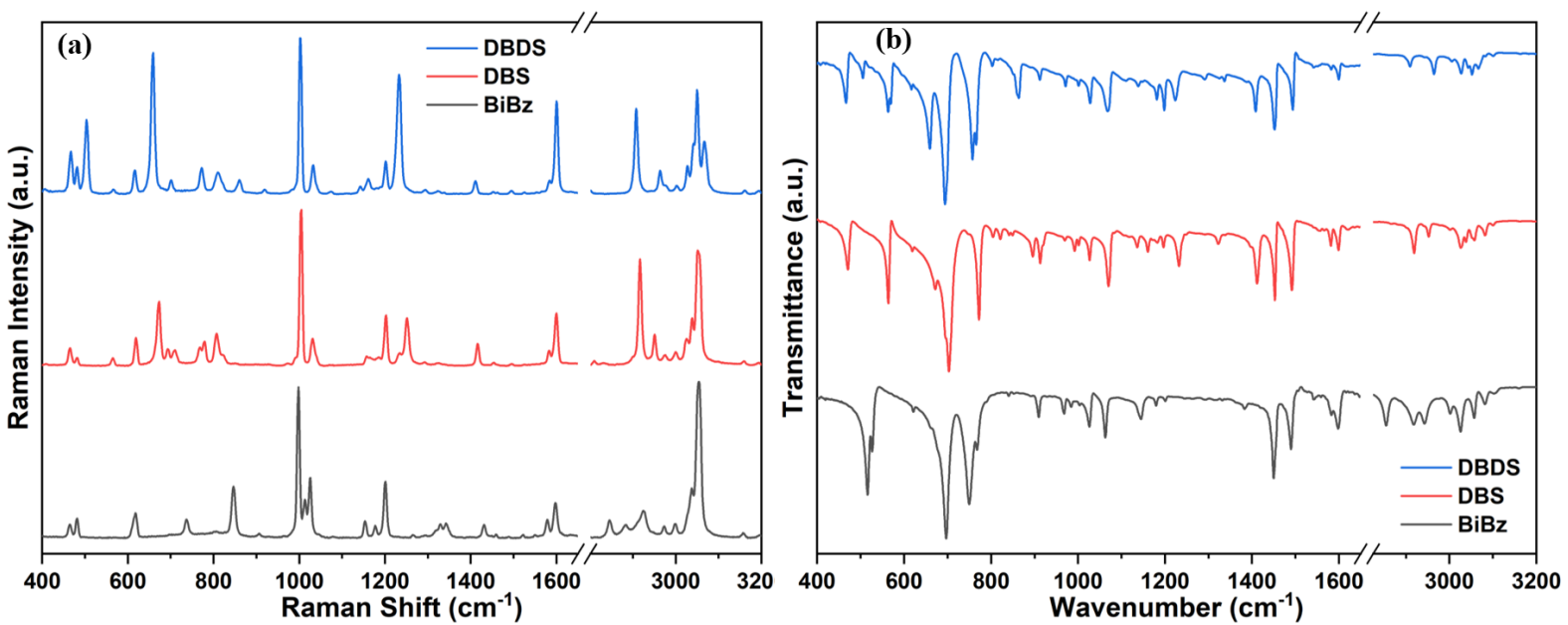

Figure 7. Experimental measured Raman (a) and IR (b) spectra of DBDS, DBS, and BiBz.

The frequency distributions of these six vibrations are generally consistent. The order from largest to smallest is asymmetric stretching, symmetric stretching, scissoring, wagging, twisting, and rocking, according to the frequency magnitude.

The characteristic vibration frequency of six different vibration behaviors in the DBDS, DBS, and BiBz is shown in Table 7. The trend is plotted in Figure 8 and the frequency is averaged by two dual vibrations. It can be found that, for the stretching vibration located in the high frequency region, when the sulfur atom in the middle of the benzyl group is lost, the stretching vibration frequency tends to decrease, while the four bending vibration frequencies in the middle frequency region tend to increase.

The most interesting aspect of these graphs is the low rocking vibration value of BiBz-2, which shows a different trend from several other conformations. This is because the frequency difference between the two dual vibration is very large. BiBz-2 is the only molecule with $C_{2 h}$ symmetry among the five dominant conformations. The rocking vibration at $748 \mathrm{~cm}^{-1}$ and $964 \mathrm{~cm}^{-1}$ are synchronous rocking and asynchronous rocking, respectively. The synchronous rocking at $748 \mathrm{~cm}^{-1}$ keeps symmetry during the vibration based on the center plane of two benzene rings. The polariseability change rate of this vibration is zero, thus the Raman activity is zero. Exhibiting extremely low frequency.

Table 7. The characteristic vibration frequency of methylene groups in different molecular.

\begin{tabular}{ccccccc}
\hline \multirow{2}{*}{ Conformation } & \multicolumn{2}{c}{ Stretching Vibration $\left.\mathbf{( c m}^{-\mathbf{1}}\right)$} & \multicolumn{3}{c}{ Bending Vibration $\left(\mathbf{c m}^{-\mathbf{1}}\right)$} \\
\cline { 2 - 7 } & Asymmetric $\left(v_{\boldsymbol{s}}\right)$ & Symmetric $\left(v_{a s}\right)$ & Scissoring $(\boldsymbol{\delta})$ & Wagging $(\omega)$ & Twisting $(\boldsymbol{\tau})$ & Rocking $(\rho)$ \\
\hline DBDS-1 & $3007 / 3025$ & $2943 / 2946$ & $1415 / 1420$ & $1221 / 1226$ & $1124 / 1127$ & $863 / 865$ \\
DBDS-2 & $3007 / 3041$ & $2947 / 2971$ & $1417 / 1431$ & $1220 / 1227$ & $1112 / 1122$ & $878 / 894$ \\
DBS & $2990 / 2991$ & 2944 & $1412 / 1416$ & $1223 / 1237$ & $1130 / 1155$ & $878 / 918$ \\
BiBz-1 & $2956 / 2968$ & $2919 / 2924$ & $1438 / 1443$ & $1279 / 1324$ & $1126 / 1170$ & $921 / 977$ \\
BiBz-2 & $2950 / 2972$ & $2920 / 2929$ & $1436 / 1452$ & $1251 / 1316$ & $1122 / 1248$ & $748 / 964$ \\
\hline
\end{tabular}



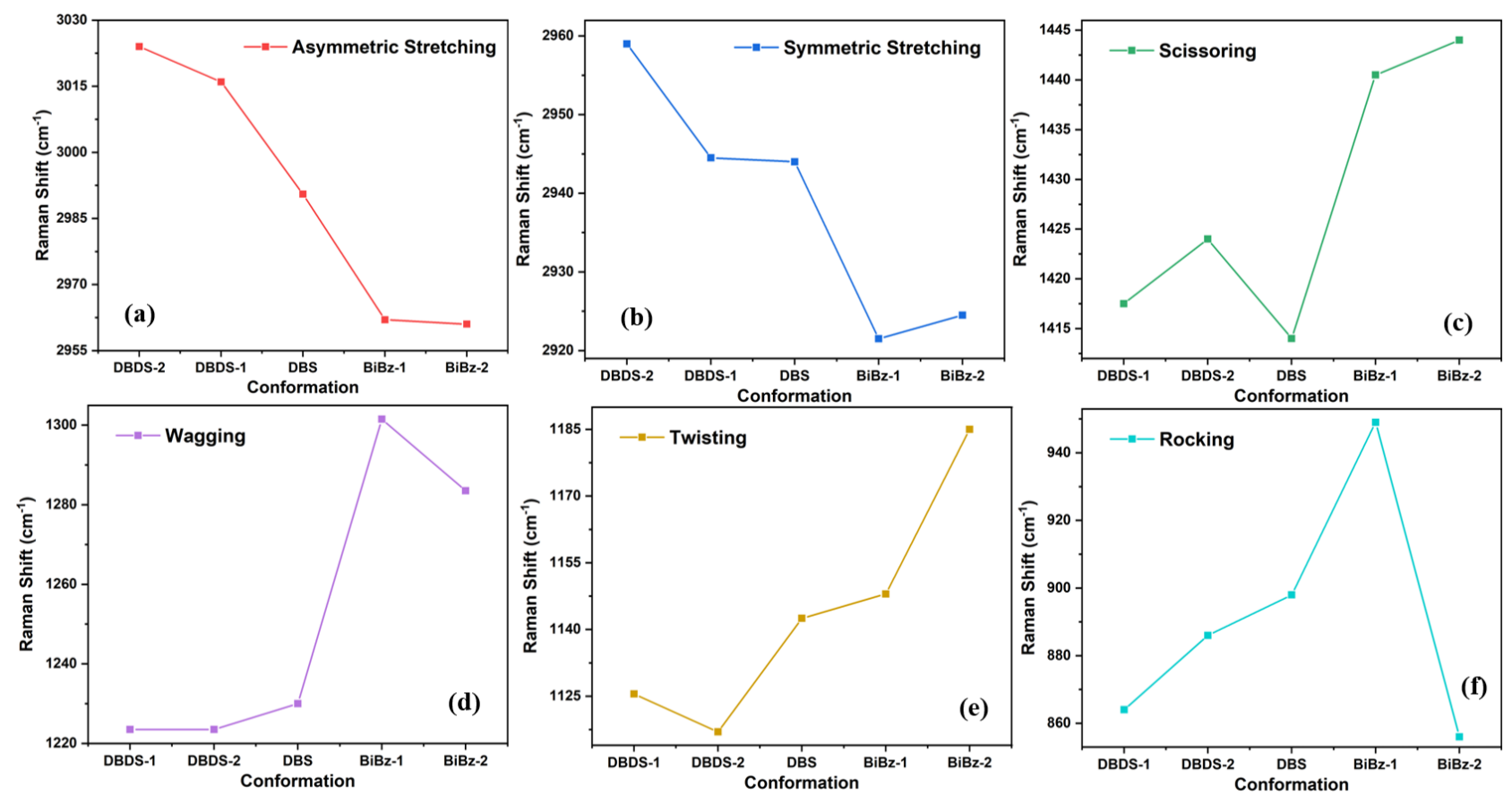

Figure 8. Tendency of different vibration behavior frequencies in the dominant conformations of DBDS, DBS, and BiBz. (a) Asymmetric Stretching; (b) Symmetric Stretching; (c) Scissoring; (d) Wagging; (e) Twisting; (f) Rocking.

\section{Conclusions}

In this paper, the vibration spectroscopy (Raman and infrared) and molecular vibrational behaviors of widely concerned molecules in sulfur corrosion phenomenon (Dibenzyl Disulfide, Dibenzyl Sulphide, and Bibenzyl) is detailedly analyzed. First, the proportion of different conformations are calculated according to Boltzmann distribution in relative Gibbs free energy via Molclus program. In order to obtain an accurate Gibbs free energy, the single-point energy is calculated in revDSD-PBEP86-D3(BJ)/may-cc-PVTZ and thermodynamic correction is calculated in the B3LYP-D3(BJ)/6-311G** level, respectively. Five dominant conformations of these three molecules were obtained, and their intramolecular interactions were detailedly discussed by $\mathrm{NCI}$ analysis.

PED based vibrational assignment of DBDS, DBS, and BiBz was performed via VEDA4 program, the normal vibration modes are assigned. Conformations weighted spectra is compared with experimentally measured spectra. It can be found that experimental spectra are in good agreement with the theoretical spectra in the B3LYP-D3(BJ)/6-311G** level with a frequency correction factor $(0.9640)$. The characteristic peak in experimental spectra is also identified to corresponding modes within a reasonable deviation. The overtone due to the anharmonic effect is also pointed out. The divergence among these molecules is discussed. It can be found that, for the stretching vibration of methylene group located in the high frequency region, when the sulfur atom in the middle of the benzyl group lost, the stretching vibration frequency tends to decrease, while the four bending vibration frequencies in the middle frequency region tend to increase.

In summary, the results presented in this paper provide a theoretical and experimental guidance for understanding the vibrational spectra and molecular vibrational behaviors of these molecules. We also believe that this article will lay a solid foundation for the development of advanced corrosive resistant materials and realization of the corrosive state monitoring. 
Supplementary Materials: The following supporting information can be downloaded at: https: / /www.mdpi.com/article/10.3390/ijms23041958/s1.

Author Contributions: Z.W.: conceptualization, methodology, software, validation, visualization, investigation, and writing - original draft preparation; R.S.: conceptualization, methodology, and writing-review and editing; J.W. and P.W.: conceptualization; Z.Z. and X.Z.: writing-review and editing; W.C.: supervision and project administration; and F.W.: funding acquisition. All authors have read and agreed to the published version of the manuscript.

Funding: This research was funded by the National Natural Science Foundation of China under grant number 51977017.

Data Availability Statement: The data presented in this study are available on request from the corresponding author.

Acknowledgments: We Would like to thank Gong at Analytical and Testing Center of Chongqing University for their assistance with FTIR test.

Conflicts of Interest: The authors declare no conflicts of interest.

\section{References}

1. Scatiggio, F.; Tumiatti, V.; Maina, R.; Tumiatti, M.; Pompili, M.; Bartnikas, R. Corrosive sulfur induced failures in oil-filled electrical power transformers and shunt reactors. IEEE Trans. Power Deliv. 2009, 24, 1240-1248. [CrossRef]

2. Scatiggio, F.; Tumiatti, V.; Maina, R.; Tumiatti, M.; Pompili, M.; Bartnkas, R. Corrosive sulfur in insulating oils: Its detection and correlated power apparatus failures. IEEE Trans. Power Deliv. 2007, 23, 508-509. [CrossRef]

3. Dahlund, M. Copper Sulphide in Transformer Insulation; CIGRE WG A2-32, Final Report, No. 378; CIGRE: Paris, France, 2009.

4. Yuan, Y.; Gao, X.; Zhou, J.; Liu, G.; Kuang, X.; Yang, L.; Liao, R. A review: Research on corrosive sulphur in electrical power equipment. High Volt. 2021, doi:10.1049/hve2.12155. [CrossRef]

5. Cong, H.; Pan, H.; Qian, D.; Zhao, H.; Li, Q. Reviews on sulphur corrosion phenomenon of the oil-paper insulating system in mineral oil transformer. High Volt. 2020, 6, 193-209. [CrossRef]

6. Toyama, S.; Tanimura, J.; Yamada, N.; Nagao, E.; Amimoto, T. Highly sensitive detection method of dibenzyl disulfide and the elucidation of the mechanism. IEEE Trans. Dielectr. Electr. Insul. 2009, 16, 509-515. [CrossRef]

7. Kamishima, S.; Ito, T.; Morishima, Y. Change in corrosivity of insulating oil caused by oxidative deterioration of the oil. IEEE Trans. Dielectr. Electr. Insul. 2012, 19, 505-509. [CrossRef]

8. Lukic, J.M.; Milosavljevic, S.B.; Orlovic, A.M. Degradation of the insulating system of power transformers by copper sulfide deposition: Influence of oil oxidation and presence of metal passivator. Ind. Eng. Chem. Res. 2010, 49, 9600-9608. [CrossRef]

9. Cong, H.; Pan, H.; Hu, X.; Zhang, M.; Li, Q. Micro-mechanism study on synergistic degradation of the oil-paper insulation with dibenzyl disulfide, hexadecyl mercaptan and benzothiophene. High Volt. 2021, 6, 448-459. [CrossRef]

10. Jaber, A.; Mehanna, N.; Oweimreen, G.; Abulkibash, A. The effect of DBDS, DBPC, BTA and DBP combinations on the corrosion of copper immersed in mineral transformer oil. IEEE Trans. Dielectr. Electr. Insul. 2016, 23, 1-7. [CrossRef]

11. Tumiatti, V.; Roggero, C.; Tumiatti, M.; Di Carlo, S.; Maina, R.; Kapila, S. IEC 62697-2012: State of the art methods for quantification of DBDS and other corrosive sulfur compounds in unused and used insulating liquids. IEEE Trans. Dielectr. Electr. Insul. 2012, 19, 1633-1641. [CrossRef]

12. Du, D.; Tang, C.; Zhang, J.; Hu, D. Effects of hydrogen sulfide on the mechanical and thermal properties of cellulose insulation paper: A molecular dynamics simulation. Mater. Chem. Phys. 2020, 240, 122153. [CrossRef]

13. Naicker, S.A.; Moodley, M. A computational study of the adsorption of corrosive sulphur on Ag surfaces. J. Mater. Sci. 2021, 56, 13386-13399. [CrossRef]

14. Zhang, Y.; Katayama, Y.; Tatara, R.; Giordano, L.; Yu, Y.; Fraggedakis, D.; Sun, J.G.; Maglia, F.; Jung, R.; Bazant, M.Z.; et al. Revealing electrolyte oxidation via carbonate dehydrogenation on Ni-based oxides in Li-ion batteries by in situ Fourier transform infrared spectroscopy. Energy Environ. Sci. 2020, 13, 183-199. [CrossRef]

15. Jianxin, W.; Weigen, C.; Zhixian, Z.; Fu, W.; Feng, Z.; Ruimin, S.; Yingying, W.; Shoufei, G. Fiber-enhanced Raman spectroscopy for highly sensitive $\mathrm{H}_{2}$ and $\mathrm{SO}_{2}$ sensing with a hollow-core anti-resonant fiber. Opt. Express 2021, 29, 32296-32311.

16. Song, R.; Chen, W.; Yang, D.; Shi, H.; Zhang, R.; Wang, Z. Aging Assessment of Oil-Paper Insulation Based on Visional Recognition of the Dimensional Expanded Raman Spectra. IEEE Trans. Instrum. Meas. 2021, 70, 1-10. [CrossRef]

17. Inaoka, S.; Iwata, K.; Saha, S. Towards the critical understanding of selected vibrational features in biologically important dicyano aromatic conjugated molecules: Importance of electron donating/withdrawal groups and geometry associated with dicyano group. Spectrochim. Acta Part A Mol. Biomol. Spectrosc. 2020, 224, 117419.

18. Wu, Y.; Lan, H.; Ning, W.; Chen, F.; Yan, G.; Cai, K. Structural dynamics and vibrational feature of N-Acetyl-D-glucosamine in aqueous solution. Spectrochim. Acta Part A Mol. Biomol. Spectrosc. 2021, 259, 119918. 
19. Muthunatesan, S.; Ragavendran, V. A study of vibrational spectra and investigations of charge transfer and chemical bonding features of 2-chloro benzimidazole based on DFT computations. Spectrochim. Acta Part A Mol. Biomol. Spectrosc. 2015, 134, 148-154. [CrossRef] [PubMed]

20. Balachandran, V.; Santhi, G.; Karpagam, V.; Rastogi, V. Structural features of the 2-amino-5-nitrobenzophenone by means of vibrational spectroscopy HF and DFT, first order hyperpolarizability, NBO, HOMO-LUMO and theromodynamic properties. Spectrochim. Acta Part A Mol. Biomol. Spectrosc. 2014, 118, 835-846. [CrossRef]

21. Sert, Y.; El-Emam, A.A.; Al-Abdullah, E.S.; Al-Tamimi, A.M.S.; Çırak, Ç.; Ucun, F. Use of vibrational spectroscopy to study 4-benzyl-3-(thiophen-2-yl)-4, 5-dihydro-1H-1, 2, 4-triazole-5-thione: A combined theoretical and experimental approach. Spectrochim. Acta Part A Mol. Biomol. Spectrosc. 2014, 126, 280-290. [CrossRef]

22. Kose, E.; Bardak, F.; Atac, A.; Karabacak, M.; Cipiloglu, M. Determination of structural and vibrational spectroscopic features of neutral and anion forms of dinicotinic acid by using NMR, infrared and Raman experimental methods combined with DFT and HF. Spectrochim. Acta Part A Mol. Biomol. Spectrosc. 2013, 114, 38-45. [CrossRef]

23. Chen, W.; Gu, Z.; Zou, J.; Wan, F.; Xiang, Y. Analysis of furfural dissolved in transformer oil based on confocal laser Raman spectroscopy. IEEE Trans. Dielectr. Electr. Insul. 2016, 23, 915-921. [CrossRef]

24. Lu, T. Molclus Program. Version 1.9.9.5. Available online: http://www.keinsci.com/research/molclus.html (accessed on 25 July 2021).

25. Frisch, M.J.; Trucks, G.W.; Schlegel, H.B.; Scuseria, G.E.; Robb, M.A.; Cheeseman, J.R.; Scalmani, G.; Barone, V.; Petersson, G.A.; Nakatsuji, H.; et al. Gaussian 16, Revision A.03; Gaussian, Inc.: Wallingford, CT, USA, 2016.

26. Stewart, J.J. Optimization of parameters for semiempirical methods VI: More modifications to the NDDO approximations and re-optimization of parameters. J. Mol. Model. 2013, 19, 1-32. [CrossRef]

27. Stephens, P.J.; Devlin, F.J.; Chabalowski, C.F.; Frisch, M.J. Ab initio calculation of vibrational absorption and circular dichroism spectra using density functional force fields. J. Phys. Chem. 1994, 98, 11623-11627. [CrossRef]

28. Grimme, S.; Antony, J.; Ehrlich, S.; Krieg, H. A consistent and accurate ab initio parametrization of density functional dispersion correction (DFT-D) for the 94 elements H-Pu. J. Chem. Phys. 2010, 132, 154104. [CrossRef]

29. Grimme, S.; Ehrlich, S.; Goerigk, L. Effect of the damping function in dispersion corrected density functional theory. J. Comput. Chem. 2011, 32, 1456-1465. [CrossRef]

30. Hariharan, P.; Pople, J. Accuracy of AH n equilibrium geometries by single determinant molecular orbital theory. Mol. Phys. 1974, 27, 209-214. [CrossRef]

31. Petersson, A.; Bennett, A.; Tensfeldt, T.G.; Al-Laham, M.A.; Shirley, W.A.; Mantzaris, J. A complete basis set model chemistry. I. The total energies of closed-shell atoms and hydrides of the first-row elements. J. Chem. Phys. 1988, 89, 2193-2218. [CrossRef]

32. Santra, G.; Sylvetsky, N.; Martin, J.M. Minimally empirical double-hybrid functionals trained against the GMTKN55 database: revDSD-PBEP86-D4, revDOD-PBE-D4, and DOD-SCAN-D4. J. Phys. Chem. A 2019, 123, 5129-5143. [CrossRef]

33. Papajak, E.; Zheng, J.; Xu, X.; Leverentz, H.R.; Truhlar, D.G. Perspectives on basis sets beautiful: Seasonal plantings of diffuse basis functions. J. Chem. Theory Comput. 2011, 7, 3027-3034. [CrossRef]

34. Lu, T.; Chen, Q. Shermo: A general code for calculating molecular thermochemistry properties. Comput. Theor. Chem. 2021,1200, 113249. [CrossRef]

35. Humphrey, W.; Dalke, A.; Schulten, K. VMD—Visual Molecular Dynamics. J. Mol. Graph. 1996, 14, 33-38. [CrossRef]

36. Zhang, J.; Lu, T. Efficient evaluation of electrostatic potential with computerized optimized code. Phys. Chem. Chem. Phys. 2021, 23, 20323-20328. [CrossRef]

37. Johnson, E.R.; Keinan, S.; Mori-Sánchez, P.; Contreras-García, J.; Cohen, A.J.; Yang, W. Revealing noncovalent interactions. J. Am. Chem. Soc. 2010, 132, 6498-6506. [CrossRef]

38. Lu, T.; Chen, F. Multiwfn: A multifunctional wavefunction analyzer. J. Comput. Chem. 2012, 33, 580-592. [CrossRef] [PubMed]

39. Lu, T.; Chen, Q. Interaction Region Indicator: A Simple Real Space Function Clearly Revealing Both Chemical Bonds and Weak Interactions. Chem.-Methods 2021, 1, 231-239. [CrossRef]

40. Jamróz, M.H. Vibrational energy distribution analysis (VEDA): Scopes and limitations. Spectrochim. Acta Part A Mol. Biomol. Spectrosc. 2013, 114, 220-230. [CrossRef] [PubMed]

41. Kashinski, D.; Chase, G.; Nelson, R.; Di Nallo, O.; Scales, A.; VanderLey, D.; Byrd, E. Harmonic vibrational frequencies: Approximate global scaling factors for TPSS, M06, and M11 functional families using several common basis sets. J. Phys. Chem. A 2017, 121, 2265-2273. [CrossRef] [PubMed]

42. Liu, Z.; Lu, T.; Chen, Q. Vibrational Spectra and Molecular Vibrational Behaviors of All-Carboatomic Rings, cyclo [18] carbon and Its Analogues. Chem.-Asian J. 2021, 16, 56-63. [CrossRef] [PubMed]

43. Halls, M.D.; Velkovski, J.; Schlegel, H.B. Harmonic frequency scaling factors for Hartree-Fock, S-VWN, B-LYP, B3-LYP, B3-PW91 and MP2 with the Sadlej pVTZ electric property basis set. Theor. Chem. Accounts 2001, 105, 413-421. [CrossRef] 